\title{
Propuesta de diseño de batería reutilizada
}

\section{Reused battery design proposal}

\author{
GARCIA-DUARTE, Oscar Enrique†’, PÉREZ-PÉREZ, Arnulfo“” y TORRES-RICO, Luis Armando’ \\ Universidad Politécnica de Juventino Rosas. Carrera de Ingeniería en Sistemas Automotrices. Hidalgo 102, Comunidad de \\ Valencia, Juventino Rosas, Gto, México. \\ "Universidad Politécnica de Juventino Rosas. Carrera de Ingeniería en Metalúrgica. Hidalgo 102, Comunidad de Valencia, \\ Juventino Rosas, Gto, México.
}

ID $1^{\text {er }}$ Autor: Oscar Enrique, Garcia-Duarte / ORC ID: 0000-0002-4781-8438, CVU CONACYT ID: 290387

ID 1 ${ }^{\text {er }}$ Coautor: Arnulfo, Pérez-Pérez / ORC ID: 0000-0001-6354-8899, CVU CONACYT ID: 176434

ID $2^{\text {do }}$ Coautor: Luis Armando, Torres-Rico / CVU CONACYT ID: 373689

DOI: $10.35429 / J O I E .2020 .13 .4 .1 .5$

Recibido Enero 10, 2020; Aceptado Marzo 30, 2020

\section{Resumen}

En este trabajo se propone una batería automotriz reutilizada basada en un estudio de tecnologías existentes. Las tecnologías aplicadas se clasificaron por los materiales utilizados en la construcción de las celdas electroquímicas, se identificaron las características importantes entre las cuales se encuentran: la capacidad de almacenamiento, el voltaje nominal de sus celdas, entre otras. Las baterías de plomo por su costo seguirán ocupando una cuota de mercado considerable para los sistemas eléctricos convencionales del automóvil, pero por sus prestaciones estas baterías no se utilizan en los sistemas de propulsión. Las baterías de níquel metal hidruro soportan un mayor estrés de trabajo, poseen mayor densidad de energía y se utilizan en los sistemas de propulsión de los vehículos híbridos. Por la demanda de energía y potencia que requieren los vehículos eléctricos se utiliza la tecnología de ion litio.

Batería automotriz, Batería reutilizada, Automovil eléctrico

\begin{abstract}
In this work, a reused automotive battery based on a study of existing technologies is proposed. The applied technologies were classified by the materials used in the construction of the electrochemical cells, the important characteristics were identified, among which are: the storage capacity, the nominal voltage of their cells, among others. Lead batteries for cost will continue to occupy a considerable market share for conventional automotive electrical systems, but due to their performance these batteries are not used in powertrains. Nickel metal hydride batteries withstand greater work stress, have a higher energy density and are used in the propulsion systems of hybrid vehicles. Due to the demand for energy and power that electric vehicles require, lithium ion technology is used.
\end{abstract}

Citación: GARCIA-DUARTE, Oscar Enrique, PÉREZ-PÉREZ, Arnulfo y TORRES-RICO, Luis Armando. Propuesta de diseño de batería reutilizada. Revista. Revista de Ingeniería Innovativa. 2020. 4-13:1-5.

$\dagger$ Investigador contribuyendo como primer autor. 


\section{Introducción}

Una batería eléctrica, acumulador eléctrico o simplemente pila, es un dispositivo que consiste en una o más celdas electroquímicas que pueden convertir la energía química almacenada en corriente eléctrica permitiendo que la corriente fluya fuera de la batería para llevar a cabo su función, el cual es alimentar un circuito eléctrico.

El diseño está pensado como pieza para convertir un vehículo convencional a uno eléctrico por lo que no competirá con baterías desarrolladas en automóviles eléctricos. Por lo que se propone un banco de baterías ligero para evitar agregar peso al automóvil y con una densidad energética $150 \mathrm{Wh} / \mathrm{kg}$ con la finalidad de logra mayor autonomía [1].

\section{Objetivo general}

Proponer un díseño de batería con materiales reutilizados capaz de generar un voltaje de $12 \mathrm{~V}$ a $110 \mathrm{Ah}$.

\section{Metodología}

Se realizo un análisis de las características de las diferentes tecnologías en baterías utilizando como foco de análisis los siguientes parámetros: Densidad de energética (Wh/kg), Capacidad de la batería (Ah), Potencia (W/kg), Eficiencia (\%), Ciclo de vida.

La batería de plomo-acido es el tipo de batería más utilizada, Tambien la más antigua de todas permaneciendo inalterada en su diseño original del Siglo XIX. Su bajo costo las hace ideales para las funciones de arranque, iluminación o soporte eléctrico, siendo utilizadas como acumuladores en vehículos de tamaño pequeño [2].

La batería níquel-cadmio es una bateriaque tiene un efecto de memoria, ya que se reduce su capacidad en cada recarga. Son utilizadas en vehículos militares, aviones o helicópteros porque los materiales para su construcción son sumamente caros. Pero tienen en exelente rendimiento en temperaturas extremamente baja.
La batería níquel-hierro es también conocida como batería de ferroníquel, tienen problemas al entregar baja potencia eléctrica. $\mathrm{L}$ abateria fue desarrollada pr Thomas Alba Edison en el año e 1903 por lo que se puede observar su tecnología es algo vieja, su densidad energética es de 33-42 Wh/kg.

La batería níquel-hidruro metálico, al utilizar niquel como elemento predominante tiende a recargarse lentamente, producen altas corrientes de descarga o sobrecarga por loque gereran demasiado calor. Contienen ciclos de vida mayores a las baterías de plomo acido, requiriendo mantenimiento constante de las celdas.

La batería de Aluminio-aire son baterías con una altacapacidad de carga de hasta 30 veces mayor a la de niquel-hierro, encontrándose aun en una fase experiemntal debido a sus problemas para recargar y a lo peligrosas que pueden ser. Tambien son conocidas como pilas de combustible debido aque sufren desgaste. Estas baterías pueden ser flexibles y tener tiempos de carga de 1 minuto aproximadamente. Debido a que se encuentra en fase esperimental y pocos productos han salido al mercado este tipo de baterías son bastante caras.

La batería Ion-litio $\left(\mathrm{LiCoO}_{2}\right)$ Oxido de Cobalto Litio es el primer material utilizado en las primer Baterias de ion-litio.

Bateria producidad industrialmente en el año de 1991 y sigue siendo el material de catodo que mejores prestaciones genera para los aparatos electrónicos principlamente. El uso de nuevos materiales como el litio ha permitido conseguir altas energías específicas, alta eficiencia, la eliminación del efecto memoria, ausencia de mantenimiento y facilidad a la hora de reciclar los desechos de Ion-litio. Disponen del doble de densidad energética que las baterías níquel-cadmio con un tamaño del orden de un tercio más pequeñas. Pero también tienen desventajas, el principal es su alto coste de producción, aunque poco a poco este se va reduciendo, son frágiles, pueden explotar por el sobrecalentamiento y deben ser almacenadas con mucho cuidado, tanto por necesitar un ambiente frío como porque debe estar parcialmente cargada. 
Al no ser una tecnología totalmente madura, y encontrarse en continuo desarrollo, los avances las hacen tener un gran margen de mejora.

Las baterías de Iones de Litio se recargan más rápido y tienen una vida útil mucho más larga que la de las baterías convencionales. Esta batería ofrece, además, mayor densidad energética, que se traduce en más autonomía en menos espacio. Son utilizados principalmente autos de alta gama y coches eléctricos por su ligereza. Su precio está por encima del resto de baterías llegando a costar casi mil dólares.

\section{Batería $\mathrm{LiFePO}_{4}$ :}

Bateria que tiene una densidad energética de $130 \mathrm{Wh} / \mathrm{kg}$ por lo que tiene una potencia considerable constituyendo una buena alternativa debido a que su uso es más estable y seguro. Tiene ciclos de viad más largos, pero con costos de producción más caros que Ionlitio $\mathrm{LiCoO}_{2}$.

\section{Batería Polímero de litio:}

Otra variación de las Ion-litio que cuenta con algunas mejoras como una densidad energética que va de $250-340 \mathrm{Wh} / \mathrm{kg}$ y una potencia más elevada. Son ligeras, eficientes y no tienen efecto memoria. En cambio, su alto costo y bajo ciclo de vida hacen de estas baterías, con aspecto blando debido a sus componentes litio y polímero, una opción no muy extendida en la actualidad.

\section{Batería ZEBRA:}

Estas baterías, también llamadas de sal fundida, trabajan a $250{ }^{\circ} \mathrm{C}$ y tienen como electrolito cloro aluminato de sodio triturado. Es una batería compleja, de mayor contenido químico, pero que consigue unas características de energía y potencia interesantes. En desuso, el electrolito se solidifica, por lo que necesita un tiempo de fundición que puede llegar a ser de dos días para que alcance la temperatura optima y ofrezca plenamente su carga. Tienen el mejor ciclo de vida de todas las baterías, pero requieren ocupar mucho espacio y su potencia es baja [4].

\section{Batería Zinc-Aire:}

Desarrolladas por una compañía suiza, y en fase experimental, pero más avanzada que las de Aluminio-Aire, estas baterías necesitan obtener el oxígeno de la atmosfera para generar una corriente. Tiene un alto potencial energético, fiabilidad y son capaces de almacenar el triple de energía que las de Ionlitio en el mismo volumen y con la mitad del coste. Según algunos expertos, el zinc se posiciona como el combustible eléctrico del futuro.

En la tabla 1 se muestra una comparativa de las diferentes tecnologías de baterías y sus principales características observándose que las baterías Ion-litio $\left(\mathrm{LiCoO}_{2}\right)$ tienen mayor densidad Energetica, pero como se observo en la anterior descripción de las bateriasno es viable para nuestro proyecto debido a que tiene un alto costo y bajo ciclo de vida. En un automóvil eléctrico es my importante los ciclos de carga y el costo de la misma debido a que aproximadamente el $37 \%$ del costo del automóvil es el costo de la batería.

\begin{tabular}{|c|c|c|c|}
\hline & $\begin{array}{l}\text { Nickel- } \\
\text { cadmio }\end{array}$ & $\begin{array}{c}\text { Plomo- } \\
\text { acido } \\
\text { Sellada }\end{array}$ & $\begin{array}{l}\text { Litio-ion } \\
\text { magnesio }\end{array}$ \\
\hline $\begin{array}{l}\text { Densidad de } \\
\text { energía } \\
\text { gravimétrica } \\
\text { (Wh/kg) }\end{array}$ & $45-80$ & $30-50$ & $100-135$ \\
\hline $\begin{array}{l}\text { Resistencia } \\
\text { interna } \mathrm{m} \Omega\end{array}$ & $\begin{array}{l}\text { 100-200 } \\
\text { Paquete } \\
\text { de 6V }\end{array}$ & $<100$ & $\begin{array}{l}25-75 \\
\text { Por celda }\end{array}$ \\
\hline $\begin{array}{l}\text { Ciclo de vida. } \\
\text { Hasta el } 80 \% \text { de } \\
\text { su capacidad } \\
\text { inicial }\end{array}$ & 1500 & $\begin{array}{l}200- \\
300\end{array}$ & $300-500$ \\
\hline $\begin{array}{l}\text { Tiempo de carga } \\
\text { rápida }\end{array}$ & $1 \mathrm{~h}$ & $\begin{array}{ll}8 \mathrm{~h} & \mathrm{a} \\
16 \mathrm{~h} & \\
\end{array}$ & $\begin{array}{ll}\text { 1h } & \mathrm{o} \\
\text { menos } & \\
\end{array}$ \\
\hline $\begin{array}{l}\text { Tolerancia de } \\
\text { sobrecarga }\end{array}$ & Moderada & Alta & Baja \\
\hline $\begin{array}{l}\text { Voltaje de celda } \\
\text { nominal }\end{array}$ & $1.25 \mathrm{~V}$ & $2 \mathrm{~V}$ & $3.6 \mathrm{~V}$ \\
\hline $\begin{array}{l}\text { Temperatura de } \\
\text { operación }\end{array}$ & $\begin{array}{l}-40^{\circ} \mathrm{C} \\
60^{\circ} \mathrm{C}\end{array}$ & $\begin{array}{l}-20^{\circ} \mathrm{C} \mathrm{a} \\
60^{\circ} \mathrm{C}\end{array}$ & $\begin{array}{l}-20^{\circ} \mathrm{C} \quad \mathrm{a} \\
60^{\circ} \mathrm{C}\end{array}$ \\
\hline $\begin{array}{l}\text { Mantenimiento } \\
\text { requerido }\end{array}$ & $\begin{array}{ll}30 \text { a } 60 \\
\text { días }\end{array}$ & $\begin{array}{l}3 \text { a } 6 \\
\text { meses }\end{array}$ & $\begin{array}{l}\text { No } \\
\text { requiere }\end{array}$ \\
\hline Toxicidad & Alta & Alta & Baja \\
\hline
\end{tabular}

Tabla 1 Comparativa de tecnologías en baterías [6]

\section{Diseño en SolidWorks para la realización de banco de baterías}

Se realizó el diseño en el programa SolidWorks para distribuir las celdas solares de manera equilibrada con una distancia de 3 milímetros entre cada celda.

GARCIA-DUARTE, Oscar Enrique, PÉREZ-PÉREZ, Arnulfo y TORRES-RICO, Luis Armando. Propuesta de diseño de batería reutilizada. Revista. Revista de Ingeniería Innovativa. 2020 


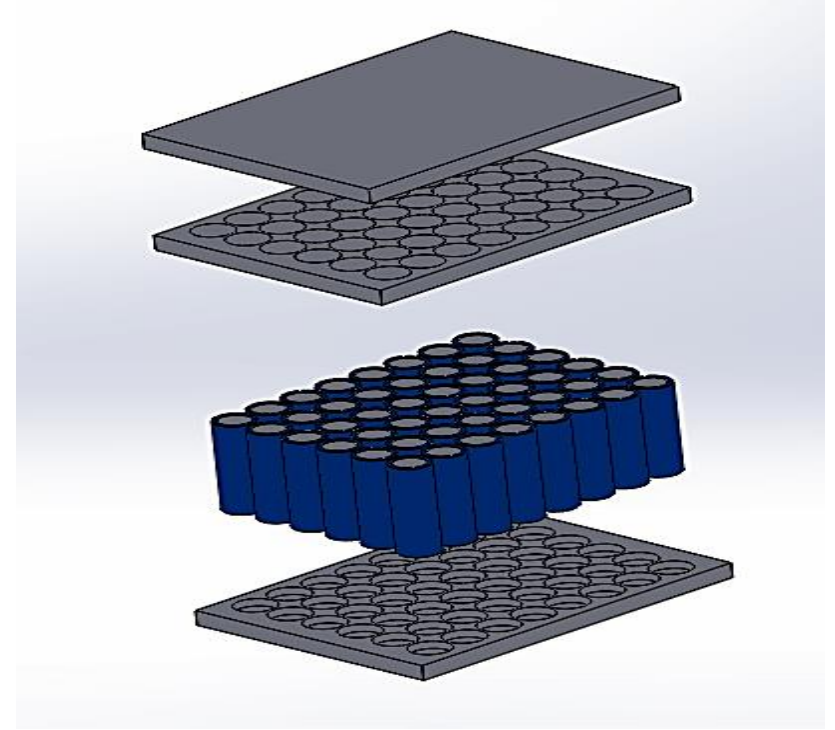

Figura 1 Banco de baterías

Fuente: elaboracion propia [solid Works]

En la Figura 1 se muestra el arreglo de las celdas de batería evitando transferencia de calor por contacto entre celda y celda. También al estar separadas las celdas logramos utilizar el aire que pasa entre las celdas para refrigerar el calor producido por la relación entre la temperatura y la velocidad que se procede en la acción química de la batería [2].

El material utilizado hacer el armazón es nylon reutilizado de la industria automotriz. Teniendo como principales características su dureza, resistencia al desgaste, resistencia al calor, resistencia a la abrasión, resistencia a la abrasión, inercia química casi total, antiadherente, inflamable, excelente dieléctrico, capacidad de amortiguación de golpes, ruido y vibraciones [3]. En la Figura 2 se muestra el armado final.

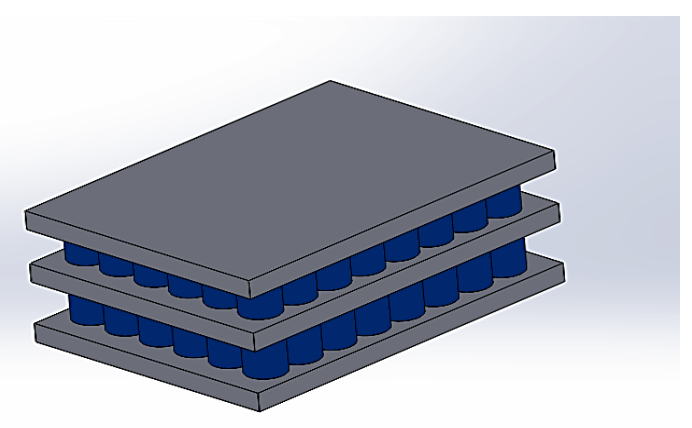

Figura 2 Banco de batería armado Fuente: elaboracion propia [solid Works]
Para el desarrollar el banco de baterías necesitábamos baterías de litio reciclables para ello se inició con una recolección de baterías de litio las cuales se encuentran en los centros de carga de las computadoras portátiles (laptops), el parámetro determinante para calificar una batería de reúso es la medición de la densidad del electrolito. Si no se dispone de un decímetro gracias a la siguiente tabla podemos conocer de forma indicativa el porcentaje de carga de la batería midiendo la tensión en los bornes (tensión en vacío) usando un voltímetro eléctrico común [5].

\begin{tabular}{|r|r|r|}
\hline \multicolumn{1}{c}{$\begin{array}{c}\text { Valor } \\
\text { Densímetro }\end{array}$} & \multicolumn{1}{c|}{$\begin{array}{c}\text { Tensión } \\
\text { Batería (V) }\end{array}$} & $\begin{array}{c}\text { Porcentaje de } \\
\text { Carga (\%) }\end{array}$ \\
\hline 1.277 & 12.73 & 100 \\
\hline 1.258 & 12.62 & 90 \\
\hline 1.238 & 12.50 & 80 \\
\hline 1.217 & 12.37 & 70 \\
\hline 1.195 & 12.24 & 60 \\
\hline 1.172 & 12.10 & 50 \\
\hline 1.148 & 11.96 & 40 \\
\hline 1.124 & 11.81 & 30 \\
\hline 1.098 & 11.66 & 20 \\
\hline 1.073 & 11.51 & 10 \\
\hline
\end{tabular}

Tabla 2 Estado de carga de celdas [3]

En la tabla 2 se muestra el voltaje de carga de una celda de batería con respecto a su porcentaje de carga. Tomándose aquellas baterías que tienen más de $1.238 \mathrm{~V}$ para reutilizar y de esta manera asegurar un $80 \%$ de eficiencia.

\section{Resultados}

En la figura 3 se muestra el arreglo serie paralelo del diseño eléctrico de la batería, obteniéndose un valor nominal de $12.06 \mathrm{~V}$.

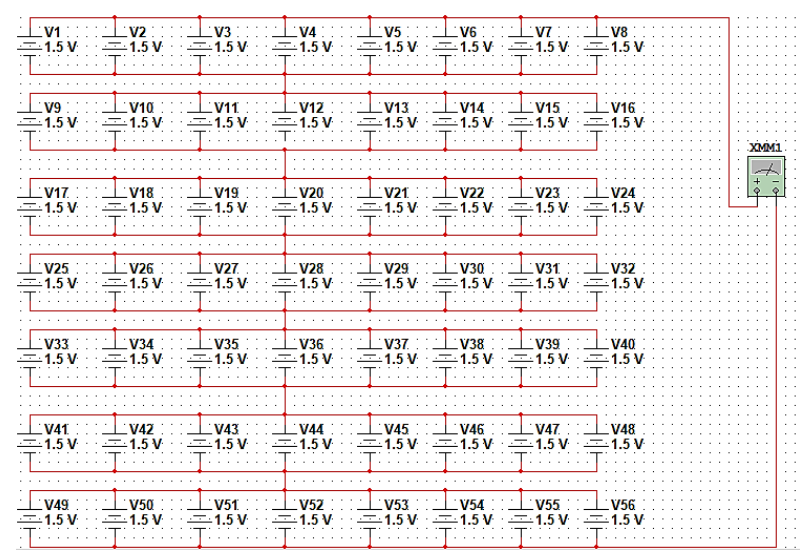

Figura 3 Arreglo serie-paralelo celdas de batería Fuente: elaboracion propia [multisim] 
Para lograr un banco de baterías se utilizaron 54 celdas de baterías reutilizadas en un arreglo serie paralelo lográndose $12.06 \mathrm{~V}$ por batería, como se puede observar en la figura 4 . Se realizaron pruebas de capacidad y duración de este mismo banco de baterías. Las pruebas consisten en conectar un motor de $12 \mathrm{v}$ para que lograra descargar por completo la batería el tiempo en descarga fue de 2 horas $10 \mathrm{~min}$. El tiempo de carga completa a partir de una descarga completa es de 1 hora $34 \mathrm{~min}$.

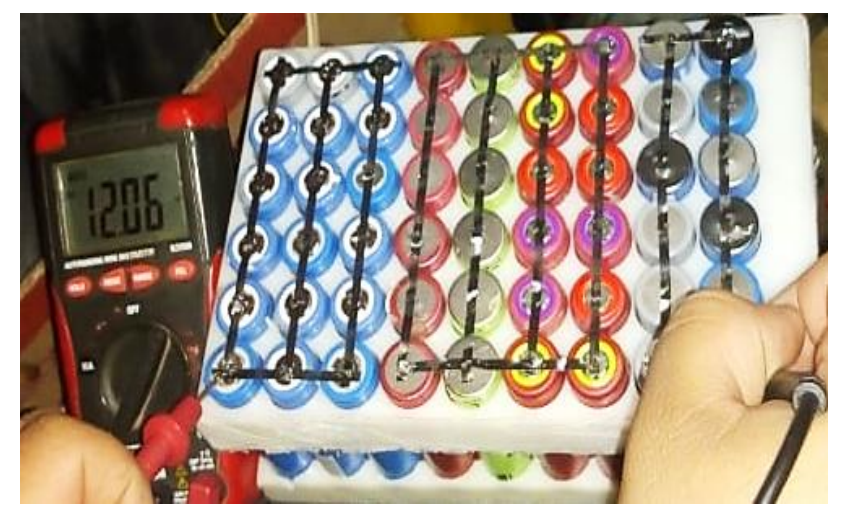

Figura 4 Circuito Serie-Paralelo de celdas de batería Fuente: elaboración propia

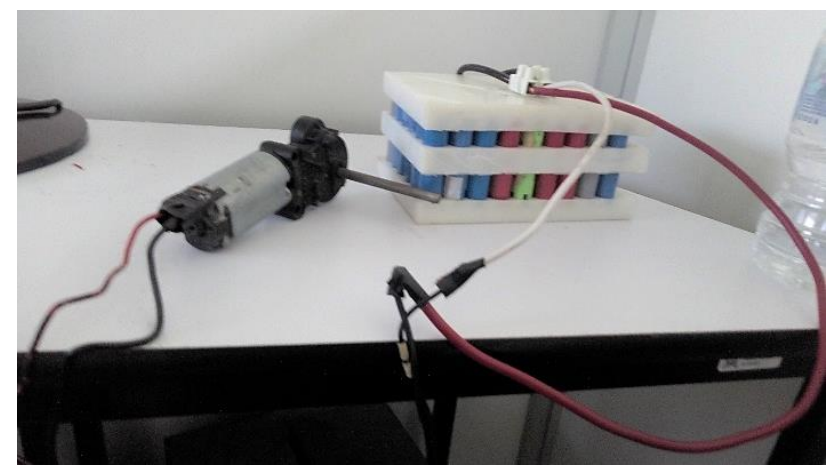

Figura 5 Proceso de prueba de descarga de batería Fuente: elaboración propia

Como se observa en la figura 5, la batería se puso a prueba con un motor de corriente directa de $12 \mathrm{~V}$ fluyendo a través del motor una corriente nominal de $1 \mathrm{~A}$.

\section{Conclusiones}

En este trabajo se logró la elaboración de una batería de $12 \mathrm{~V}$ con elementos raramente utilizados como elementos de reusó. Teniéndose varias ventajas entre ellas un costo considerablemente bajo, un casi nulo procesamiento de los elementos que la componen debido a que las celdas obtenidas de baterías de computadora portátil solo fueron desmontadas de la misma y la maquila de placa de nylon no necesita de herramientas muy sofisticadas o costosas.
Obteniéndose una batería con mínimo un $80 \%$ de vida útil. Reflejándose en un ciclo de vida de aproximadamente 300 ciclos de carga profunda.

\section{Referencias}

[1] Mandy Concepcion. (2011). Sistemas Automotrices Hibridos Avanzados. Editorial Mandy Concepcion.

[2] Canales M. María; Ávila V. José. Fisicoquimica. UNAM. México 1999.

[3] Vega de K. Juan. Principios y Aplicaciones de la energía fotovoltaica y de las baterías. Ediciones UC. México 2018.

[4] Trashorras M. Jesus. Vehiculos Electricos. Ediciones Paraninfo S.A. España 2019.

[5] Bautista Z. Francisco. Técnicas de muestreo para manejadores de recursos naturales. Universidad Autonoma de México. Mexico 2004.

[6] Michael Emir (Noviembre 2018). Baterías: Comparativa Litio, NiMh, NiCd, LiPo, Plomo. El Salvador. ScAcKk AnD NoOne. TOP-CODING.

http://topcoding.blogspot.com/2012/02/bat erias-comparativa-litio-nimh-nicd.html. 